\title{
O CONCEITO DE MAL RADICAL ${ }^{1}$
}

Adriano CORREIA ${ }^{2}$

- RESUMO: A noção de mal radical aparece em Kant no contexto da discussão da religião nos limites da simples razão e busca dar conta da complexa relação entre o respeito pela lei moral e o amor-próprio na definição do móbil para a ação. $\mathrm{Na}$ busca por identificar o fundamento da propensão para o mal no homem, Kant se vê diante da dificuldade de ter de articular natureza e liberdade, e ainda que a noção de mal radical possa conservar algumas ambigüidades, permite conceber uma noção de responsabilidade compatível com uma inata propensão para o mal. Neste texto busco explicitar alguns passos fundamentais na construção do conceito por Kant.

- PALAVRAS-CHAVE: mal radical, liberdade, respeito, amor-próprio, responsabilidade.

Na filosofia de Kant, a noção de mal radical, tal como aparece no texto A religião dentro dos limites da simples razão, opera como articulação e explicação das oscilações no vínculo entre razão e vontade, assim como do conflito entre respeito pela lei moral e amor-próprio. O mal radical, tal como o concebe Kant, está intimamente relacionado ao problema da liberdade, mas particularmente também ao que ele julga ser uma predisposição natural do homem a inclinar-se a ceder às suas apetições. Já em sua reflexão sobre a moral, mas principalmente nas suas considerações acerca de uma re-

1 Artigo recebido em 07/2005; aprovado para publicação em 08/2005.

2 Prof. Dr. - Universidade Federal da Bahia; adrianocorrei@yahoo.com.br 
ligião moral, ou de uma religião nos limites da simples razão, aparece o exame de um mal intrínseco à natureza do homem, compreendida esta como "o fundamento subjetivo do uso de sua liberdade em geral (sob leis morais objetivas), que antecede todo ato que cai nos sentidos". ${ }^{3}$ Assim, quando ele afirma que há uma disposição natural para o mal no homem, está se referindo ao fato de que, para o uso de sua liberdade, o homem sempre admite uma máxima fornecida a si mesmo pelo arbítrio, e de que a qualidade boa ou má das máximas adotadas está de antemão determinada pelo insondável primeiro princípio de sua aceitação, que poderia ser atribuído universalmente ao homem. Com efeito, o mal radical não se refere a alguma forma particular de mal ou a alguma de suas manifestações nas ações dos homens, mas mais propriamente ao fundamento da possibilidade de todo mal moral. O que define, portanto, a adoção de máximas consoantes ou contrárias à lei moral é esse primeiro princípio inato - não como algo dado na experiência, como um objeto determinante do arbítrio pela inclinação ou como um instinto natural, mas inato apenas no sentido de que é posto "como fundamento antes de todo o uso da liberdade dado na experiência (da primeira juventude remontando ao nascimento), e que é representado como existente no homem desde seu nascimento; não que o nascimento seja justamente a causa disto". ${ }^{4}$ Para Kant, importa notar que o termo inato indica que a disposição de ânimo boa ou má e a adoção de um fundamento bom ou mal como máxima segundo a qual alguém quer se comportar não é adquirida no tempo, mas é não apenas adotada pelo livre-arbítrio, como também se refere universalmente ao uso total da liberdade.

Quando Kant se referiu ao mal antes de seu livro sobre a religião, ele o havia concebido como sendo um desenvolvimento incompleto no homem da sua capacidade para o bem. Ele compreendia que uma vontade é livre na medida em que é determinada pelo princípio moral, como forma do querer em geral, e é não-livre na medida em que é determinada por um objeto, isto é, por algo que lhe é externo, ainda que a felicidade própria. Assim, uma vontade livre é sempre uma vontade autônoma, determinada por si própria, enquanto uma vontade não livre é uma vontade heterônoma. ${ }^{5}$ Disto se segue que uma vontade livre pode ser apenas uma vontade boa, consoante à lei moral, enquanto uma vontade não livre é apenas uma vontade fraca ou imperfeitamente boa, pois do que se expôs não seria concebível a vontade ser ao mesmo tempo livre e má. Por conseguinte, na medida em que o homem quer livremente, ele quer o bem, e quando se desvia é porque

\footnotetext{
3 A religião dentro dos limites da simples razão, p. 368 da trad. bras.

4 Idem, p. 369 da trad. bras. Cf. Henry ALLISON, Kant's theory of freedom, p. 147.

5 Fundamentação da metafísica dos costumes [BA 88 e 95], pp. 86 e 91 da trad. port.
} 
sua vontade se vê vítima de suas inclinações, ou seja, no fim das contas, quando se desvia do bem, ele de fato não quer livremente. Não obstante, as inclinações não são razão ou motivo suficiente para a ação de um agente livre, se não são incorporadas espontaneamente em sua máxima, de modo que "o mal deve estar radicado mais na vontade que em nossa dada natureza sensível". 6

Mesmo o pior vilão é alguém dotado não de uma vontade má, mas desafortunadamente carente de vontade livre, dominado por suas inclinações, o que nos leva a supor que em vez de um vilão, ele é de fato um débil inocente, digno de piedade, não de censura. ${ }^{7}$ Assim, o mal moral não é possível se tivermos em vista seja a santidade divina, que possui uma vontade pura, na medida em que não possui inclinações, seja o comportamento animal, completamente determinado por suas inclinações, por si mesmas amorais e inocentes, nem boas nem más. Não obstante, se considerarmos que uma ação não boa é uma ação carente de liberdade da vontade e completamente determinada pelas inclinações, o mal moral também não é concebível entre os homens. Mas também não o é a liberdade e, por conseguinte, a responsabilidade. Com a doutrina do mal radical como uma propensão universal para o mal no homem, Kant opera uma sensível transformação na sua teoria, sustentando basicamente que deve ser possível escolher livremente entre o bem e o mal, embora esta decisão não seja determinada por qualquer princípio particular. O que antes, na Fundamentação da metafísica dos costumes, por exemplo, aparecia como tendência a abrir uma exceção na lei em benefício próprio, passa a ser uma propensão inata ao mal, ainda que um tanto paradoxalmente resultante de uma livre escolha. A doutrina do mal radical é então uma tentativa de dar uma fundamentação filosófica adequada à liberdade moral, e ao mesmo tempo, de tornar possível a concepção da responsabilidade pelos atos não conformes à lei moral.

Uma primeira conseqüência que se segue do que foi exposto logo acima é que a lei moral terá de ter realidade objetiva para que a liberdade e todos os outros conceitos morais também a tenham, tal como aparece na terceira parte da Fundamentação da metafísica dos costumes. No caso específico da liberdade, ela é conhecida como que por uma inferência a partir da obediência à lei, como propriedade da causalidade da vontade. Por isso, na razão prática a teoria da facticidade da lei antecede a teoria da liberdade. Em outras palavras, primeiro a teoria da lei, depois a teoria do objeto: de um lado porque a realidade do objeto depende da realidade da lei; de outro, porque a realidade objetiva da lei não é realizada "objetualmente", mas é

6 Henry ALLISON, "Reflection on the banality of (radical) evil", p. 175

7 Emil L. FACKENHEIM, “Kant and radical evil”, pp. 264-265. Cf. p. 260. 
expressa e assegurada no respeito por ela. A liberdade, no entanto, só é efetiva na medida em que leva a cabo ações consoantes à lei moral. Eu conheço a liberdade da vontade como uma condição de respeito pela lei moral. Mas conhecer o condicionado pela condição que o condiciona não é conhecer a coisa mesma, mas somente uma relação determinante sobre ela. No que se refere à liberdade, no entanto, não posso conhecer mais que isto, resigna-se Kant. No momento em que provo que sou livre quando obedeço à lei moral, entro numa espécie de servidão voluntária, por assim dizer: a consciência da liberdade vem da consciência da lei e a consciência da lei é a consciência de que ela me obriga.

A moral baseia-se em um conceito de homem como ser livre, sem necessitar de nenhum outro ente para assegurar o dever moral. O dever não decorre, no entanto, do fato de o homem ser livre, mas a liberdade é que é conhecida efetivamente somente a partir do fato de que o homem possui deveres e se sente obrigado pela lei moral. A questão é: se eu devo, eu posso, e se posso e devo, sou livre. A obediência à lei moral é que me torna possível saber que sou livre. A liberdade é conhecida somente como condição do dever. Embora o dever possa ser conectado aos sentimentos morais, a liberdade só o é por meio do dever, indiretamente.

Não posso, portanto, começar uma teoria moral a partir da liberdade, em Kant. Temos uma relação direta com a lei que define a nossa moralidade. Desse modo, não preciso de Deus, por exemplo, para saber o que é o bem ou o mal. Por onde entra a religião então? Por que precisamos dela, uma vez que a moral basta-se a si própria por meio da razão pura prática? A questão é que para que a obrigação moral, o dever, a liberdade e mesmo a vida boa façam sentido, a minha razão não cobra objetos, mas a minha sensibilidade, pelo fato de eu ser um agente sensível, precisa lidar com objetos, porque sem objetos eu não posso agir. A moral, por si, não precisa da determinação de um fim para determinar a vontade e, por conseguinte, as ações. A moral é formal: só precisa de lei, não de meta, embora sem o objeto, mesmo o homem sabendo como deve agir, não sabe para onde. No domínio estrito das ações não se pode prescindir de um fim (que, por assim dizer, deve sair da moral, tendo em vista que esta permanece sendo a condição formal de todas as metas).

O problema que se apresenta ao homem não é o de agir moralmente ou não, mas, uma vez agindo moralmente, qual mundo ele, como agente sensível, produziria. Por isto mesmo, na sua ação ele não levaria em conta somente a lei moral (neste caso, o fazer do mundo de acordo com uma idéia), mas também iria querer compatibilizar a existência do mundo moral com a realização do máximo bem por meio do homem sensível. A vontade quer que o mundo exista e a razão prática quer fazer um mundo no qual possa 
agir. É nesse sentido que a moral conduz à religião (mas nunca o contrário), por esta poder conceber a idéia de um legislador universal compatibilizador.

Por o agente ser sensível, ele necessariamente busca a felicidade como fim último. A felicidade é um princípio que nos fornece uma meta final por nossa própria natureza sensível. A eudaimonia é apoiada num forte conceito de natureza e de harmonia entre o homem e a natureza. O homem, por sua natureza sensível, deve fazer o máximo para buscar realizar no mundo o seu "bem supremo". A lei moral não pede nenhum objeto, mas como manda viver moralmente e o homem é um ser sensível, as ações morais cobram objetos sensíveis; esta é talvez a única ponte que se possa estabelecer entre a lei moral e a felicidade, em Kant. Dito de outro modo, a razão não pode recusar a pergunta sobre aonde conduz a obediência à lei moral, não por ela estar ligada à lei moral, mas por estar condicionada pela finitude e sensibilidade do sujeito que age. Com efeito, Kant admite que mesmo que não haja uma conexão necessária entre felicidade e moralidade, assume também que não deve haver uma necessária oposição. E ainda que ele pudesse louvar a auto-satisfação daquele que se dá conta da própria virtude no seguimento da lei moral, não deixava de considerar que a felicidade, como componente fundamental do sumo bem, secundando a moralidade, não deve ser desconsiderada. ${ }^{8}$

A religião faz sentido se tivermos em consideração que a razão não pode ficar indiferente à pergunta da sensibilidade pelas conseqüências do seguimento da lei moral, do agir conforme a ela. É a resposta às indagações postas pela sensibilidade que vai dar um conteúdo prático aos conceitos da religião. Desse modo, deve-se supor um Bem Supremo, moral, que seja capaz de unir os dois momentos: racionalidade e sensibilidade, moralidade e felicidade. O Bem Supremo é a lei moral cujas conseqüências não ferem a sensibilidade. Este Bem Supremo só pode existir, pensa Kant, se houver um criador do mundo; é um acordo entre moral e felicidade só realizável tendose um Deus moral como condição.

Na busca por identificar o fundamento da propensão para o mal no homem, Kant se vê diante da dificuldade de ter de conciliar natureza e liberdade. Com efeito, se se compreende o mal como decorrente de algum condicionamento natural, ainda que seja uma fraqueza, necessariamente o homem seria inimputável, pois não poderia ser considerado efetivamente responsável (na medida em que não seria livre) pelas ações que desencadeasse. Kant, por razões óbvias, busca evitar uma tal compreensão, sustentando que a propensão para o mal "é uma tendência deliberativa e, como

8 Cf. Crítica da razão prática, pp. 212-214 e 224s. 
tal, completamente distinta de um impulso natural ou algo assim". ${ }^{9}$ Esta tendência deliberativa equivale a uma propensão a permitir que considerações não morais provenientes das inclinações venham a pesar mais que as considerações morais - operando assim, nas palavras de H. Allison, como uma espécie de "lei permissiva" para uma imoralidade limitada.

A receptividade à lei moral é uma disposição também originária para o bem, uma disposição para tomar o respeito pela lei moral como móbil das ações, uma disposição, por fim, à personalidade. O mal radical é uma espécie de ataque à própria disposição para o bem, para se deixar tocar pela lei. O mal seria esta propensão universal para não receber o respeito pela lei como móbil. A especificidade da religião consiste em aliar o respeito pela lei a uma disposição para a realização de ações boas. Para se compreender o conceito de mal, é necessário entender a relação entre o livre-arbítrio e o recebimento das máximas decorrentes do respeito pela lei moral como móbil. Grosso modo, o mal equivale a tomar como regra do agir a relação de prazer e desprazer para com os objetos. O mal moral é sempre definido, portanto, por uma relação de resistência à lei moral, como causa oposta à ação segundo a lei moral, que se opõe à obediência. O mal moral age contra o bem moral. Assim, para seguir na moralidade não basta desenvolver o princípio do bem em nós (respeito pela lei), mas também combater uma causa antagônica do mal em nós.

Kant insiste na consideração não apenas de que há uma propensão efetiva para o mal, mas também de que essa propensão deve ser atribuída a toda a espécie. Para H. Allison, esta atribuição não deve ser tomada simplesmente por uma generalização empírica, baseada na afirmação kantiana de que a prova da universalidade da propensão ao mal se faz evidente se considerarmos a infinidade de ações más dos homens, sem que seja dada qualquer prova formal efetiva. Essa pretensão de universalização pode ser tomada apenas como um postulado sintético a priori, cuja justificação ou dedução, embora não seja dada por Kant, pode ser reconstruída a partir de alguns pressupostos da sua teoria moral. Em primeiro lugar, deve-se admitir a impossibilidade de se atribuir uma universal propensão ao bem a agentes finitos afetados pela sensibilidade como os homens - essa propensão ao bem consistiria em uma disposição, baseada em uma máxima, para subordinar o estímulo egoísta ao estímulo moral, isto é, a preferir a lei moral à satisfação das necessidades assimiladas ao desejo de felicidade inerente aos homens como animais sensíveis. Se pudéssemos conceber tais seres, não sujeitos à tentação de adotar máximas contrárias à lei, teríamos de admitir

9 Henry ALLISON, Kant's theory of freedom, p. 153 (grifos no original). 
não apenas a inexistência do mal no mundo, mas também a não necessidade de a lei se apresentar na forma de um imperativo. Com efeito, a lei moral se apresenta sob a forma de um imperativo, diz Kant, justamente porque não podemos pressupor uma vontade perfeitamente boa (santa) em seres sensíveis, uma vontade em que "o querer coincide já por si necessariamente com a lei". ${ }^{10}$ Junto a essa impossibilidade, o rigorismo sustentado por Kant, a não tolerar um meio-termo moral - a compreensão de que alguém pode ser moralmente parcialmente bom ou mau ou ser indiferente -, requer a concepção de uma propensão universal para o mal, pois a nossa natureza sensível impõe que sejamos não apenas agentes morais autônomos, mas também sujeitos a desejos e inclinações não completamente controláveis ou assimiláveis aos ditames da moralidade.

O ponto essencial é que o próprio fato de só obedecermos à lei relutantemente (ungern) indica não apenas uma ausência de santidade, mas também uma propensão efetiva a subordinar considerações morais a nossas necessidades como seres sensíveis, isto é, uma tendência a nos deixar ser tentados ou 'induzidos' pela inclinação a violar a lei moral, ainda que reconhecendo a sua autoridade. Mais precisamente, uma vez que esta abertura à tentação não é uma mera conseqüência do fato de que temos uma natureza sensível, mas reflete uma atitude que tomamos em relação a essa natureza, ou melhor, um valor que depositamos em suas solicitações, ela pode ser imputada. E uma vez que essa avaliação resulta de uma preocupação com nosso bem-estar, que é inseparável de nossa natureza de animais racionais, está 'enraizada na própria humanidade' (a predisposição à humanidade) e é, por conseguinte, universal. ${ }^{11}$

Não obstante, assim como Kant não concebe a possibilidade de uma propensão universal para o bem, também não admite na sua reflexão a concepção de uma vontade diabólica, a querer o mal pelo mal, pois não é possível escolher a recusa da lei. Com efeito, com o imperativo categórico ele parece pensar ter enunciado a fórmula aplicada pela mente humana para distinguir o certo do errado. Ele supunha, ademais, que esta capacidade de discernir o que se deve fazer para ser honrado e virtuoso, "o conhecimento daquilo que cada homem deve fazer, e, por conseguinte saber, é também pertença de cada homem, mesmo do mais vulgar", 12 pois a liberdade deve ser pressuposta como uma propriedade da vontade de todos os seres racionais. Não são necessárias nem a ciência nem a filosofia para se ter acesso aos conceitos morais, diz Kant, visto que "todos os conceitos morais têm a sua sede e origem completamente a priori na razão, e isto tanto na razão hu-

10 Fundamentação da metafísica dos costumes [BA 39], p. 49 da trad. port. (grifos no original).

11 Henry ALLISON, Kant's theory of freedom, p. 157 (grifos no original).

12 Fundamentação da metafísica dos costumes, [BA 21], p. 36 da trad. port. 
mana mais vulgar como na especulativa em mais alta medida". ${ }^{13}$ Assim, se desse modo temos de supor, um imoralismo extremo seria simplesmente absurdo (absurdum morale), uma forma de a razão tentar denegar ou contradizer a si mesma. O mal moral só é possível devido não a uma corrupção da razão legislativa, mas à propensão a adotar outro móbil para a ação em vez da lei, sem deixar de reconhecê-la. Esse mal não se deve nem apenas ao fato de que possuímos sensibilidade, pois isto implicaria sermos maus por natureza, ${ }^{14}$ nem à concepção de uma vontade absolutamente má. Esta última, com efeito, é inaplicável ao homem, pois um sujeito que elevasse a oposição pura e simples à lei moral como motivo para a ação seria um ente diabólico.

Kant julga que haja uma disposição originária para o bem na natureza humana, assentada na sua disposição à animalidade, como ente vivo, em seu amor-próprio; na sua disposição à humanidade, como ente vivo e racional, em sua capacidade de pôr a razão a serviço da inclinação; na sua disposição à personalidade, como ente racional e ao mesmo tempo responsável, na sua razão prática incondicionalmente legisladora, a mover a ação sem qualquer outro móvel senão ela própria. Desse modo,

(...) a malignidade da natureza humana não é, pois, maldade, se tomarmos esta palavra no sentido estrito; a saber, como uma intenção (princípio subjetivo das máximas) de admitir o mal, enquanto mal, para motivo em sua máxima (pois esta é diabólica), mas muito antes perversão do coração, o qual, portanto, denomina-se também um coração mau. ${ }^{15}$

Ainda que se possa afirmar que haja uma propensão universal para o mal na natureza humana, pensa Kant, não se pode negar que a disposição originária para o bem na natureza humana, a lei moral como princípio objetivo do agir em todo ser racional, é não apenas presumível, mas também inextirpável. É isto que ele tem em mente quando afirma que

(...) o homem (mesmo o pior) não renuncia, quaisquer que sejam as máximas, à lei moral, nunca de maneira rebelde (com recusa da obediência). Esta se impõe, muito antes, a ele, de uma maneira irresistível; e se nenhum outro motivo age em contrário, acolhê-la-á também na máxima suprema, como fundamento suficiente de determinação do arbítrio, isto é, ele seria bom moralmente. ${ }^{16}$

Não é possível então conceber uma maldade desinteressada ou uma resistência positiva ao bem: "aquilo que Kant expressamente denega é a

13 Idem., [BA 34], p. 46 da trad. port.

14 "O mal só pode ter sua origem no moralmente mau (não nos meros limites de nossa natureza)." A religião dentro dos limites da simples razão, p. 383 da trad. bras. Cf. p. 378.

15 Idem, p. 379 da trad. bras. Cf. pp. 371-373 (grifos no original).

16 Idem., p. 378. 
perspectiva de que pudesse haver indiferença em relação à moralidade e sua lei, de que se pudesse pensar um mundo no qual a lei moral não tivesse vigência necessária". ${ }^{17} \mathrm{O}$ que temos em Kant é a fraqueza da natureza humana ou o mal utilitário, por assim dizer. Embora em seu rigorismo ele não possa admitir um meio-termo moral entre o bem e o mal, ele admite a concepção de vários graus ou estágios de realização da propensão universal ao mal. O primeiro grau ou estágio do mal radical seria a fragilidade da natureza humana, implicada no fato de que mesmo acolhido o bem na máxima do arbítrio, como motivo incontornável, subjetivamente, na ação a máxima se mostra mais fraca que a inclinação - tal como expressa o apóstolo Paulo: "não pratico o que quero, mas faço o que detesto" (Romanos, 7, 15). Há a vontade boa, mas falta a realização. Um outro nível do mal radical seria a impureza do coração, a tendência a misturar motivos morais com motivos não morais, como se a lei por si só não fosse motivo suficiente, de modo que mesmo "as ações conformes ao dever não são executadas puramente por dever" ${ }^{18}$ Por fim, temos a corrupção ou perversidade do coração humano, assentada no fato de que são acatadas no arbítrio máximas más, que expõem a lei moral subordinada a motivos não morais, provenientes das inclinações ou desejos. Assim se tem um coração mau, nos termos de Kant, na medida em que nesse último estágio se opera uma inversão por meio da qual a lei é substituída pelo amor-próprio como móbil da ação, de modo que é como se o mal fosse cometido deliberadamente. Não obstante, para Kant, nesse estágio em que a auto-satisfação é o motor predominante das ações, mas em que não é denegada a lei moral, vige um sistemático auto-engano. Em todos esses estágios, há a possibilidade de que se dêem ações conformes à lei, mas ainda que pratique apenas boas ações o homem é, nesses casos, sempre mau. O que distingue um homem bom de um homem mau não é propriamente o conteúdo do que cada um admite em suas máximas, mas a ordem de subordinação que um ou outro admite como princípio supremo de determinação de todas as máximas; ou seja, um homem só é verdadeiramente mau quando reverte a ordem dos motivos, quando submete a lei moral a uma lei do amor próprio ou da felicidade. Esse mal é radical, diz Kant, "porque corrompe o fundamento de todas as máximas; ao mesmo tempo também, como propensão natural, não pode ser extirpado por forças humanas", ${ }^{19}$ o que não desobriga da tarefa constante de tentar dominá-lo.

Assim, tal como nas Escrituras, o mal só é compreensível como uma queda, como "pecado", uma fraqueza diante da sedução (Gênesis, 3, 1-12), e

17 Oswaldo GIACOIA, "Reflexões sobre a noção de mal radical", p. 192. Cf. p. 189.

18 A religião dentro dos limites da simples razão, p. 374 da trad. bras.

19 Idem., p. 379 da trad. bras (grifos meus). 
permanece sendo uma "culpa original", pois não apenas não podemos admitir uma perversão natural do próprio homem como temos ainda de supor a vigência latente da vontade boa, também para que "reste a esperança de uma volta ao bem do qual se desviou" ${ }^{20}$ Seria esta basicamente a distinção entre as doutrinas do mal radical e a do pecado original, por sua vez bastante semelhantes, pois para Kant o pecado original é uma espécie de impossibilidade moral, tendo em vista que gera uma situação em que há uma obrigação moral sem que haja ao mesmo tempo uma liberdade moral, uma possibilidade de que se repare o dano originário com uma conversão do espírito:

Ambas doutrinas afirmam uma radical perversão no homem como ele é agora, uma perversão ocasionada por ele próprio. Ambas afirmam que, na medida em que esta perversão é radical, nenhuma simples reforma gradual pode eliminá-la. Para eliminá-la, é necessário um ato total de conversão, um ato de redenção, a criação de um novo homem. Mas enquanto, de acordo com a doutrina cristã, apenas Deus pode redimir o homem decaído, Kant afirma, e tem de afirmar, que o homem pode redimir a si mesmo. ${ }^{21}$

Mas "quem fará sair o puro do impuro", como pergunta Jó, na Bíblia (Jó 14, 4)?. Para Kant, uma árvore boa dá maus frutos apenas porque é boa segundo a disposição, mas não segundo o ato. Não obstante, como "o mal provém da liberdade", mas não a elimina definitivamente, deve ser possível o reerguimento do mal para o bem, pois se devemos fazê-lo, e de fato o devemos, necessariamente também temos de podê-lo - pois a razão não ordena o que é impossível -, ainda que nossas forças cheguem apenas ao ponto em que nos tornemos dignos de receber uma insondável "ajuda vinda do mais alto" ou uma "cooperação sobrenatural". A restauração da disposiç̧ão original para o bem em nós não consiste, portanto, na restauração do respeito perdido pela lei moral, por si inextirpável em nós como seres racionais, mas na restauração da santidade das máximas, da sua conformidade com a lei moral. Essa restauração só é possível através de uma revolução no caráter, promovida pelo próprio homem, como a gerar seu próprio nascimento sob o aspecto de um homem novo, mas não a partir de um princípio determinante e sim da sua própria liberdade de escolha. ${ }^{22}$ Pois se o caráter não é obra da natureza, devemos supor que o homem seja capaz de defini-lo, e mesmo de redefini-lo, por uma escolha entre o bem e o mal. E ainda que não possamos

20 Idem., p. 375 e 384. Cf. pp. 384-385 e 389.

21 FACKENHEIM, Emil L. Kant and radical evil, p. 270.

22 A religião dentro dos limites da simples razão, p. 386 da trad. bras. Poucos anos depois de ter escrito a Religião, Kant afirma que o mal moral é autodestrutivo: "o mal moral tem a qualidade inseparável de sua natureza que ele é em suas intenções (sobretudo em relação a outros intencionados de modo igual) contrário e destruidor de si mesmo, e assim dá lugar ao princípio (moral) do bem, embora por um progresso lento". À paz perpétua, p. 71 da trad. bras. (Ak. p. 379). 
extirpar de nós a imperfeição, não podemos nos esquivar do dever de nos tornarmos melhores, pois não temos de buscar a felicidade, mas de ser virtuosos, ou seja, nos tornarmos dignos dela. Se considerarmos ainda a melancólica avaliação kantiana da vida como um fardo ou um "tempo de provação" e o seu profundo temor pelo autodesprezo, teremos de considerar que a meta mais elevada na vida de um indivíduo é tornar-se digno de uma felicidade que é inalcançável nessa Terra. Assim,

a moral tampouco é propriamente a doutrina de como nos fazemos felizes, mas de como devemos tornar-nos dignos da felicidade. Só se a religião é acrescida a ela, realiza-se também a esperança de tornar-nos algum dia partícipes da felicidade na proporção em que cuidamos de não sermos indignos dela. ${ }^{23}$

O que está em questão, nos diferentes momentos da reflexão kantiana sobre o mal radical é, portanto, não apenas a necessidade de se conceber a responsabilidade moral, a imputabilidade, mas ainda a impossibilidade ou o caráter autodestrutivo do querer o mal pelo mal, da conversão do mal em uma lei universal ou um fim em si mesmo, como se a oposição deliberada à lei moral fosse uma espécie de impossibilidade psicológica e o extremo imoralismo um absurdo. ${ }^{24}$ Nesse sentido, e de acordo com o que expus acima, permite-nos compreender mesmo a estatura dos grandes vilões da história e da literatura - o Iago de Shakespeare, o Claggart no Billy Budd, de Melville, e os vários personagens de Dostoievski -, em sua deliberada inversão da relação entre lei moral e interesse próprio. O século passado, todavia, nos legou a estirpe dos vilões sem estatura, a realizar um mal extremo de um modo desinteressado, por assim dizer, ou interessado apenas de um modo mediado - penso aqui no evento totalitário. Este mal não limitado sequer pelo interesse próprio acaba por portar em si uma destrutividade também ilimitada. A perversão da obediência, convertida em único móbil da ação, a atentar contra a autonomia, acabou por provar que os corações maus dos grandes vilões são menos assustadores que a conduta desinteressada e não utilitária dos subordinados de baixa estatura. É como se o mal destes vilões sem grandeza, por não ter motivação identificável nos móbiles indexados no quadro tradicional das perversões - como o egoísmo, a ga-

23 Crítica da razão prática, A 234, p. 209 da trad. bras (grifos no original).

24 Cf. Henry ALLISON, Kant's theory of freedom, p. 150. Na Fundamentação da metafísica dos costumes [BA 19], p. 34-35 da trad. port. aparece o seguinte: "Em breve reconheço que posso em verdade querer a mentira, mas que não posso querer uma lei universal de mentir; pois, segundo uma tal lei, não poderia propriamente haver já promessa alguma, porque seria inútil afirmar a minha vontade relativamente a minhas futuras ações a pessoas que já não acreditariam em minha afirmação, ou, se precipitadamente o fizessem, me pagariam na mesma moeda. Por conseguinte, a minha máxima, uma vez arvorada em lei universal, destruir-se-ia a si mesma necessariamente." Cf. acima a nota 20 . 
nância, a cobiça, o ressentimento, o desejo de poder, a covardia -, indicasse que estamos diante de indivíduos que cometeram o mal pelo mal, e não como meio para a aquisição de algum benefício próprio. Estes indivíduos que não parecem querer abrir uma exceção para si mesmos e sim universalizar a mentira, além de pôr em questão a própria lei moral ou o próprio fundamento da legalidade - não tinham, obviamente, como ser tomados em consideração por Kant, e certamente seriam incluídos por ele na categoria dos entes diabólicos.

CORREIA, A. The concept of radical evil. Trans/Form/Ação, (São Paulo), v.28(2), 2005, p.83-94.

- ABSTRACT: The concept of radical evil appears in Kant's theory when he discusses the religion in the limits of the mere reason and aims explain the complex relationship between respect for the moral law and the self-love, for establish the motive of the action. By aiming identify the basis of human inclination to evil, Kant is faced with the trouble of have to put nature and freedom in connection. Despite of the concept of radical evil retain some ambiguity, it allows conceive a notion of responsibility suitable to an inherent inclination to evil. In this paper is my purpose to explain some basic moments of Kantian formulation of that notion.

- KEYWORDS: Radical Evil, Freedom, Respect, Self-love, Responsibility.

\section{Referências bibliográficas}

ALLISON, Henry. Kant's theory of freedom. Cambridge University Press, 1995.

Reflection on the banality of (radical) evil. In: Id. Idealism and freedom: essays on Kant's theoretical and practical philosophy. Cambridge University Press, 1996, p. 169-82.

FACKENHEIM, Emil L. "Kant and radical evil". In: CHADWICK, Ruth (ed.). Immanuel Kant. Critical assessments (vol. III: Kant's moral and political philosophy). Nova York: Routledge, 1995, pp. 259-273.

GIACOIA Jr., Oswaldo. Reflexões sobre a noção de mal radical. Studia Kantiana. Revista da Sociedade Kant Brasileira. Vol. I, nº 1, set. 1998, pp. 183-202.

KANT, I. Kants Werke. Berlim: Walter de Gruyter \& Co., 1968.

. Crítica da razão prática. Trad. Valerio Rohden. São Paulo: Martins Fontes, 2002.

. Fundamentação da metafísica dos costumes. Trad. Paulo Quintela. Lis-

boa: Edições 70, 1997.

À paz perpétua. Trad. Marco Zingano. Porto Alegre: L\&PM Editores, 1989

A religião dentro dos limites da simples razão (1 ${ }^{a}$ parte). Trad. Tânia M. Bernkopf. Col. Os Pensadores. São Paulo: Abril Cultural, 1974. 